\title{
Mechano-Enzymatic Deconstruction with a New Enzymatic Cocktail to Enhance Enzymatic Hydrolysis and Bioethanol Fermentation of Two Macroalgae Species
}

\author{
Sameh Amamou ${ }^{1}$, Cecilia Sambusiti ${ }^{1}$, Florian Monlau ${ }^{1,2}$, Eric Dubreucq ${ }^{1}$ \\ and Abdellatif Barakat 1,3,* (D) \\ 1 UMR, Ingénierie des Agropolymères et des Technologies Emergentes (IATE), CIRAD, Montpellier SupAgro, \\ INRA, Université de Montpellier, 34060 Montpellier, France; sameh.amamou@supagro.fr (S.A.); \\ cecilia.sambusiti@gmail.com (C.S.); Florian.Monlau@Apesa.Fr (F.M.); Eric.Dubreucq@supagro.fr (E.D.) \\ 2 APESA, Plateau Technique, Cap Ecologia, Avenue Fréderic Joliot Curie, 64230 Lescar, France \\ 3 AgroBioSciences, Mohammed VI Polytechnic University, Lot 660-Hay Moulay Rachid, \\ Ben Guerir 43150, Morocco \\ * Correspondence: abdellatif.barakat@inra.fr; Tel.: +33-(0)4-99-61-25-81; Fax: +33-(0)4-99-61-30-76
}

Received: 14 November 2017; Accepted: 7 January 2018; Published: 17 January 2018

\begin{abstract}
The aim of this study was to explore the efficiency of a mechano-enzymatic deconstruction of two macroalgae species for sugars and bioethanol production, by using a new enzymatic cocktail (Haliatase) and two types of milling modes (vibro-ball: VBM and centrifugal milling: $\mathrm{CM}$ ). By increasing the enzymatic concentration from 3.4 to $30 \mathrm{~g} / \mathrm{L}$, the total sugars released after $72 \mathrm{~h}$ of hydrolysis increased (from 6.7 to $13.1 \mathrm{~g} / 100 \mathrm{~g}$ TS and from 7.95 to $10.8 \mathrm{~g} / 100 \mathrm{~g}$ TS for the green algae $U$. lactuca and the red algae G. sesquipedale, respectively). Conversely, total sugars released from G. sesquipedale increased (up to $126 \%$ and $129 \%$ after VBM and CM, respectively). The best bioethanol yield ( $6 \mathrm{~g}_{\text {eth }} / 100 \mathrm{~g}$ TS) was reached after $72 \mathrm{~h}$ of fermentation of $U$. lactuca and no increase was obtained after centrifugal milling. The latter led to an enhancement of the ethanol yield of G. sesquipedale (from 2 to $4 \mathrm{~g} / 100 \mathrm{~g}$ TS).
\end{abstract}

Keywords: bioethanol; enzymatic hydrolysis; macroalgae; mechanical pretreatment

\section{Introduction}

Over the last decades, the world has been facing critical economic and environmental issues, such as the exhaustion of fuels, environmental pollution and climate change, combined with the increase of the world population. These issues led to the expansion of research and development on renewable and sustainable biofuels [1,2]. Both lignocellulosic biomasses and algae constitute sustainable sources of bioenergy and biomolecules (i.e., surfactant, bioethanol, biogas and biodiesel) and they represent promising alternative sources to petroleum-based fuels and chemicals.

In particular, macro- and/or micro-algae permit us to overcome the major limitations associated with lignocellulosic plants [3]. Macroalgae, also called seaweeds, represent renewable abundant biomasses, which could be easily cultivated in aquatic environment. Thus, they do not compete with land use, and water consumption necessary for terrestrial plants.

Furthermore, macroalgae are characterized by a higher growth rate than lignocellulosic biomasses and higher hydrolysable sugar contents than crops with almost no lignin [4-6]. Macroalgae are multicellular photosynthetic organisms divided into three major groups: green, red and brown algae, according to the thallus color derived from natural pigments and chlorophylls $[4,7]$. Generally, the amounts of carbohydrates vary between $25-60 \%, 30-60 \%$ and $30-50 \%$ dry wt. for green, red, 
and brown algae, respectively. In particular, green algae are mainly composed of mannan, ulvan, starch and cellulose, while red algae are mainly composed of carrageenan (up to 75\% dry wt.) and agar (up to $52 \%$ dry wt.) as polysaccharides [6].

Several researches have reported the use of marine alga biomass as bioethanol feedstock. Different macroalgae groups such as Gelidium amansii [8], Gracilaria salicornia [9] and Kappaphycus alvarezii belonging to red seaweed and green algal species such as Ulva spp. have been considered as potential sources for conversion to bioethanol. As the interests in seaweeds were expanding, intense research was required for an efficient use of this biomass. However, it still faces technical and economic challenges and still depends on the development of eco-friendly pretreatment and conversion methods [10]. Since this step is often required to facilitate the enzymatic hydrolysis of macroalgae and their further sugars and bioethanol conversion. So far, the most common pretreatments used to enhance the hydrolysis and thus bioethanol production of macroalgae are physical (wet oxidation, thermal, milling and oven drying), chemical (acidic and alkaline), and thermo-chemical pretreatments [10]. However, one of the major drawbacks of using thermal and thermo-chemical pretreatments is the possible formation of organic acids and furan derivatives, which can inhibit bioethanol fermentation [11,12]. In addition, to find the most sustainable and cost-effective pretreatment, another challenge of producing bioethanol and interesting molecules from G. sesquipedale (red) and green U. lactuca (green) macroalgae is to find the specific enzymes able to efficiently hydrolyze their polysaccharides (Figure 1). Mechanical fractionation of biomass is one promising route that can contribute to a future sustainable dry biorefinery without water consumption and without waste production. Grinding or dry fractionation can be easily introduced in a biorefinery scheme improving the overall sustainability process [13]. Thus, coupling mechanical fractionation with enzymes is a promising biorefinery scheme of algae biomass valorization. In addition, the use of this natural enzymatic cocktail (i.e., Haliatase) coupling to mechanical fractionation has never yet been investigated in algae biomass biorefineries. Thus, the main objectives of this study were the following:

(i) Explore the efficiency of a new enzymatic cocktail to hydrolyze polysaccharides of two macroalgae species (red and green sp.)

(ii) Study the effect of two mechanical pretreatments, centrifugal milling (CM) and vibro ball milling (VBM) on enzymatic hydrolysis and bioethanol fermentation of the two-macroalgae species (red G. sesquipedale and green U. lactuca) (Figure 1).

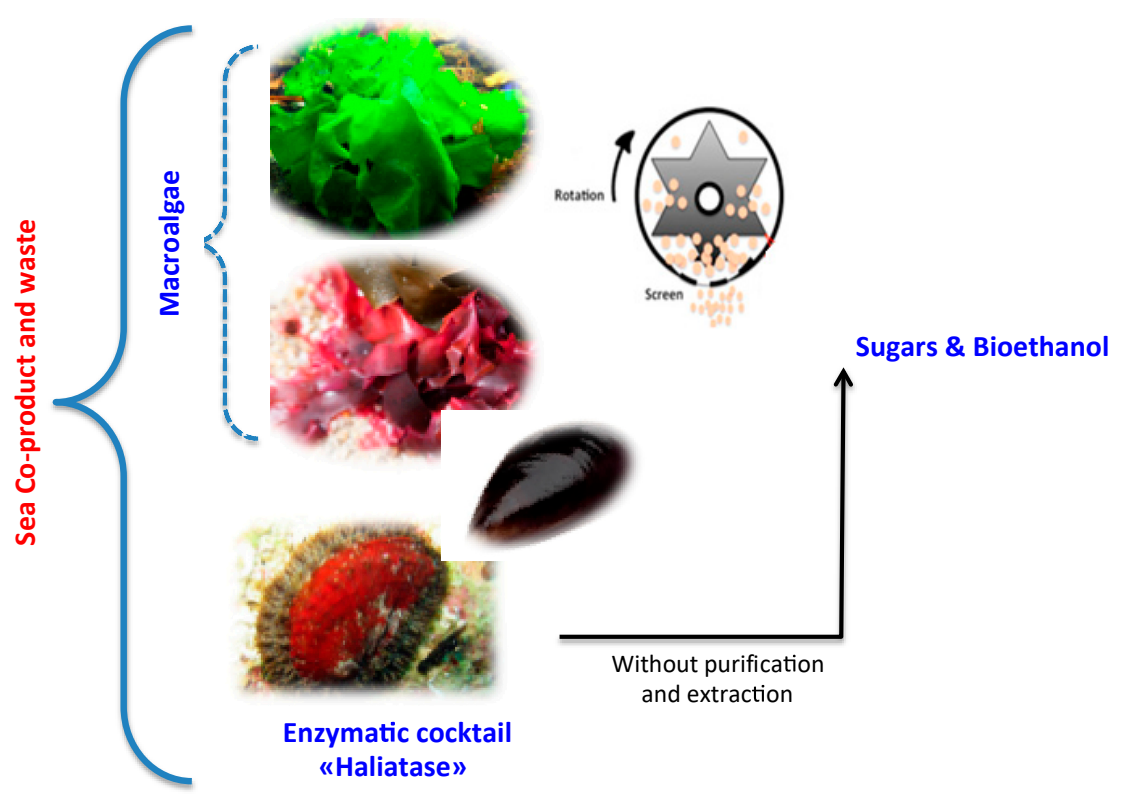

Figure 1. Mechano-enzymatic pretreatment and deconstruction of macroalgae developed in this study. 


\section{Results and Discussion}

\subsection{Chemical Composition}

The chemical compositions of both red G. sesquipedale and green U. lactuca macroalgae are shown in Table 1. U. lactuca had higher ash content (32 g/100 g TS) than G. sesquipedale (11 g/100 g TS). These values are in agreement with literature studies that reported ash values ranging from 11 to $34 \mathrm{~g} / \mathrm{TS}$ and from 9 to $20 \mathrm{~g} / 100 \mathrm{~g}$ TS, for green and red macroalgae, respectively [8,14,15]. Similar protein content (13 and $16 \mathrm{~g} / 100 \mathrm{~g}$ TS) was observed for U. lactuca and G.sesquipedale, in accordance with literature data for red (10-16 g/100 g TS) and green (12-21 g/100 g TS) macroalgae [14-16].

Table 1. Chemical composition of red G. sesquipedale and green $U$. lactuca Values correspond to mean \pm SD (standard deviation) of measurement performed in duplicate.

\begin{tabular}{ccc}
\hline Composition & G. sesquipedale & U. lactuca \\
\hline TS (g/100 g FM) & $91 \pm 0$ & $90 \pm 0$ \\
VS (g/100 g TS) & $78 \pm 0.1$ & $62 \pm 0.7$ \\
Ash (g/100 g TS) & $11 \pm 0.3$ & $32 \pm 0.7$ \\
C (g/100 g TS) & $34.7 \pm 0.5$ & $26.8 \pm 1.5$ \\
N (g/100 g TS) & $2.5 \pm 0.1$ & $2.3 \pm 0.4$ \\
H (g/100 g TS) & $5.7 \pm 0.05$ & $4.5 \pm 0.6$ \\
S (g/100 g TS) & $2.1 \pm 0.02$ & $3.7 \pm 0.12$ \\
Proteins (g/100 g TS) & $19.9 \pm 0.82$ & $15.9 \pm 1.91$ \\
Total Sugars (g/100 g TS) & 30.9 & 25.8 \\
\hline Monomeric sugars * & & $15.2 \pm 1.01$ \\
Glucose (g/100 g TS) & $9.6 \pm 0.06$ & n.d. \\
Galactose (g/100 g TS) & $20.3 \pm 0.78$ \\
Arabinose (g/100 g TS) & $0.9 \pm 0.06$ & n.d. \\
Xylose (g/100 g TS) & n.d. & $7.1 \pm 0.18$ \\
Rhamnose (g/100 g TS) & n.d. & $0.5 \pm 0.04$ \\
Fucose (g/100 g TS) & n.d. & $3.86 \pm 0.01$ \\
Glucuronic acid (g/100 g TS) & $0.3 \pm 0.03$ & $1.15 \pm 0.00$ \\
Galacturonic acid (g/100 g TS) & $3.0 \pm 0.06$ & \\
\hline
\end{tabular}

n.d.: Not detected; * Monosaccharide profile of polymeric carbohydrates determined after acid hydrolysis and HPLC quantification; SD: standard deviation.

Total sugar content of $U$. lactuca and G. sesquipedale were 25.8 and $30.9 \mathrm{~g} / 100 \mathrm{~g}$ TS, respectively. Similar sugar content was reported by Jard et al. [16] for red and green macroalgae. As reported by Jung et al. [7], the red alga G. sesquipedale was mainly composed of glucose, galactose, and agar, while U. lactuca consisted of glucose, xylose, and rhamnose. Glucuronic and galacturonic acids were also detected in both algae with values of 5.01 and $3.32 \mathrm{~g} / 100 \mathrm{~g}$ TS for the green and red algae, respectively. However, it is noteworthy that the chemical composition of macroalgae presents a great variability in the literature, which is related to several factors, such as species, geographical origin, season, environmental, and physiological variations, but also to the analytical method used for their characterization.

\subsection{Particle Size of Macroalgae}

Particle size of the untreated and milled macroalgae is reported in Figure 2. After milling, a lower mean particle size was obtained for the green alga U. lactuca (147-161 $\mu \mathrm{m})$ than the red alga G. sesquipedale (201-355 $\mu \mathrm{m})$, which can be explained by the lower particle size distribution of the untreated green algae biomass $(289 \mu \mathrm{m})$ than the red one $(472 \mu \mathrm{m})$. Furthermore, it was observed that for the red alga, CM was more effective than VBM in particle size reduction (Anova $p$-values $<0.05$ ) (Figure 2); while for the green alga similar effect of VBM and CM was noticed with a slightly higher effect of VBM but not significant with an Anova $p$-values of 0.59 . This could be explained by the 
high ash content (around 30\%) and a possible synergistic impact between the mineral ash and the mechanical process (i.e., VBM) as previously mentioned by Motte et al. [13]. Indeed, they highlighted in their study that a mineral-vegetal co-milling in a VBM could significantly reduce the final particle size of the lignocellulosic biomass compared to a simple milling of lignocellulosic biomass.

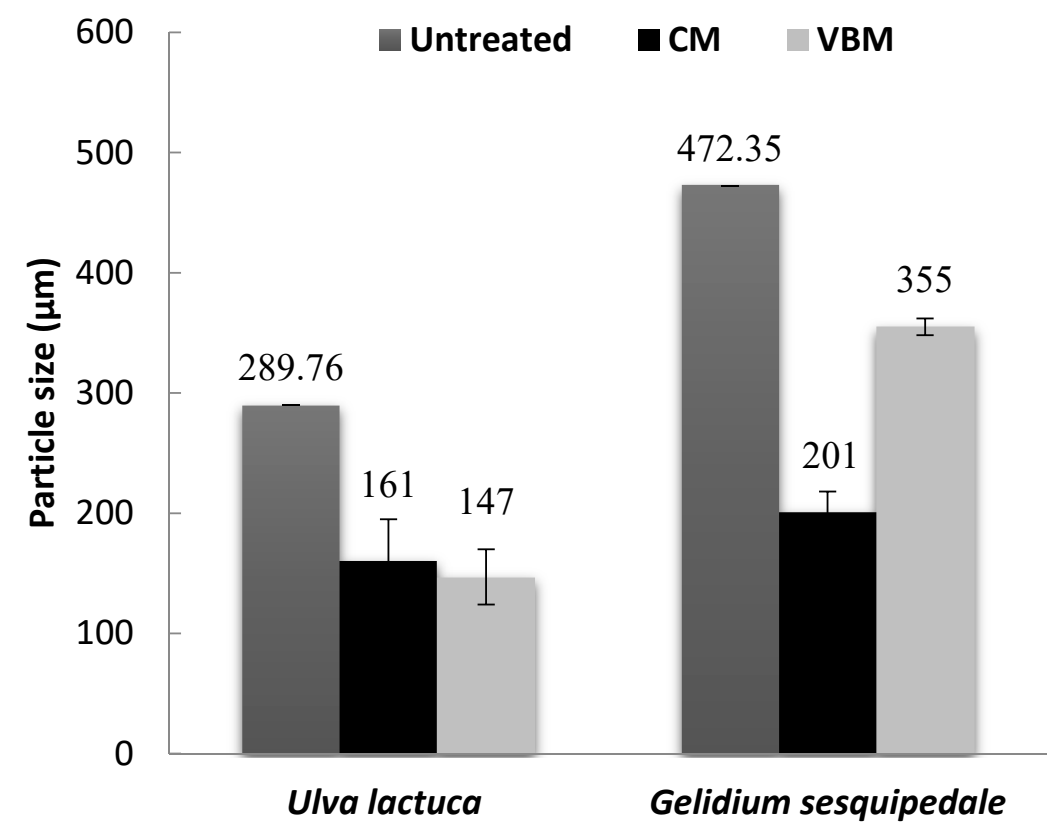

Figure 2. Mean particle sizes of untreated and milled algae biomass. Values correspond to mean $\pm \mathrm{SD}$ (standard deviation) of measurement performed in duplicate.

\subsection{Effect of Haliatase Cocktail Activity on Sugars Yield of Untreated Macroalgae}

The effect of Haliatase dosage on total sugars released during enzymatic hydrolysis of untreated U. lactuca and G. sesquipedale was investigated (Figure 3). For both macroalgae, the increase of the enzymatic concentration led to higher total sugars released. By increasing the enzymatic concentration from 3.4 to $30 \mathrm{~g} / \mathrm{L}$, the total sugars released after $72 \mathrm{~h}$ of hydrolysis varied from 6.7 to $13.1 \mathrm{~g} / 100 \mathrm{~g}$ TS and from 7.9 to $10.8 \mathrm{~g} / 100 \mathrm{~g}$ TS for U. lactuca and G. sesquipedale, respectively (significant difference with Anova $p$-values <0.05) (Table 2).

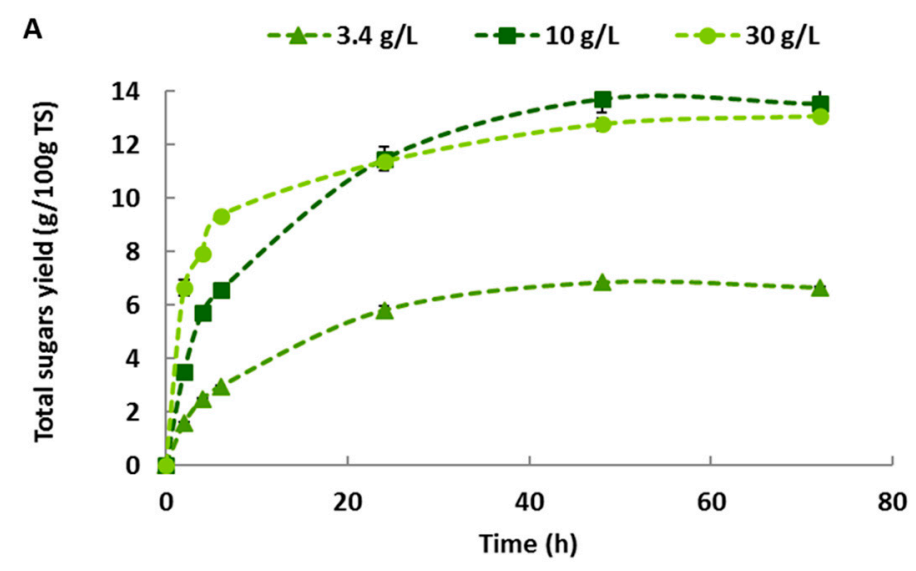

Figure 3. Cont. 


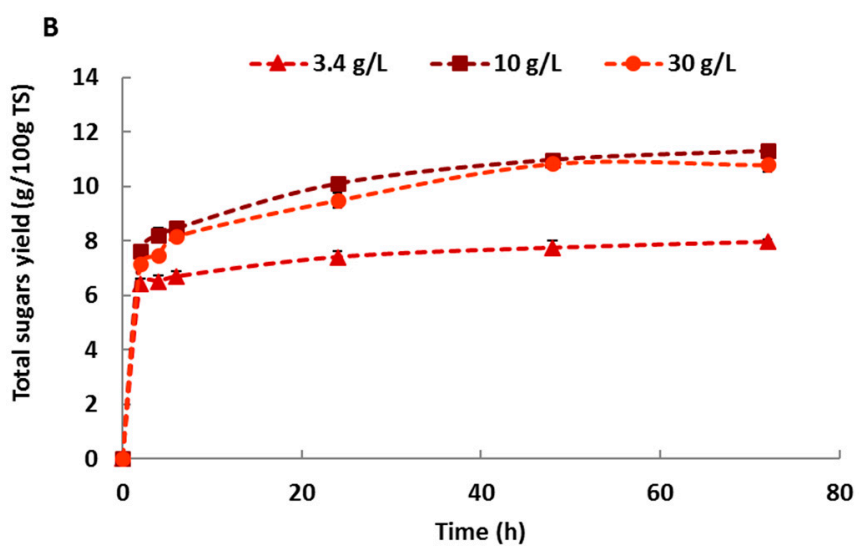

Figure 3. Total sugars released after $72 \mathrm{~h}$ of enzymatic hydrolysis for various enzyme dosages $(3.4,10$ and $30 \mathrm{~g} / \mathrm{L}$ ) for both untreated (A) Ulva lactuca and (B) Gelidium sesquipedale.

Table 2. Total sugar yields (g/100 $\mathrm{g}$ TS) obtained after $72 \mathrm{~h}$ of enzymatic hydrolysis of untreated and milled algae with an enzyme dosage of $3.4,10$ and $30 \mathrm{~g} / \mathrm{L}$.

\begin{tabular}{ccccc}
\hline Samples & Enzyme Loading & $\mathbf{3 . 4} \mathbf{~ g / L}$ & $\mathbf{1 0} \mathbf{~ g / L}$ & $\mathbf{3 0} \mathbf{~} / \mathbf{L}$ \\
\hline \multirow{2}{*}{ Green alga: } & Untreated & $6.66 \pm 0.04$ & $13.52 \pm 0.51$ & $13.05 \pm 0.16$ \\
Ulva lactuca & Centrifugal milling & $6.48 \pm 0.40$ & $13.46 \pm 0.61$ & $13.24 \pm 0.37$ \\
& Vibro ball milling & $6.70 \pm 0.35$ & $13.33 \pm 0.37$ & $12.49 \pm 0.20$ \\
\hline Red alga: & Untreated & $7.96 \pm 0.09$ & $11.30 \pm 0.13$ & $10.79 \pm 0.26$ \\
Gelidium & Centrifugal milling & $10.28 \pm 0.06$ & $13.28 \pm 0.19$ & $13.09 \pm 0.48$ \\
sesquipedale & Vibro ball milling & $10.03 \pm 0.20$ & $12.70 \pm 0.11$ & $13.59 \pm 0.34$ \\
\hline
\end{tabular}

However, the increase of enzyme concentration from 10 to $30 \mathrm{~g} / \mathrm{L}$ did not lead to a further enhancement of total sugar yield of both red and green algae witch is assumed with Anova $p$-values of 0.13 and 1.55, respectively, for green and red algae. Finally, for both algae species, the major soluble sugar released during the enzymatic hydrolysis was glucose which is very pertinent in the case of ethanol production using the Saccharomyces cerevisae strain. Glucose released after $72 \mathrm{~h}$ of enzymatic hydrolysis varied from 5.8 to $10.5 \mathrm{~g} / 100 \mathrm{~g}$ TS for $U$. lactuca and from 1.5 to $4.1 \mathrm{~g} / 100 \mathrm{~g}$ TS for G. sesquipedale after increasing the enzymatic dosage from 3.4 to $30 \mathrm{~g} / \mathrm{L}$ (significant difference with Anova $p$-values < 0.05) (Table 3 ). If the results of glucose yields were not significantly different from $10 \mathrm{~g} / \mathrm{L}$ to $30 \mathrm{~g} / \mathrm{L}$ for red algae (Anova $p$-values of 0.95 ), they were for green algae (Anova $p$-values $<0.05$ ). Cho et al. [17] reported an enzymatic saccharification of Gelidium amansii using Celluclast 1.5 L (endoglucanase: $(8.4 \mathrm{U} / \mathrm{mL})$, Viscozymes L ( $\beta$-glucanase: $1.2 \mathrm{U} / \mathrm{mL}$ ) and a mixture of both enzymes. They obtained a glucose concentration of $5.5 \mathrm{~g} / \mathrm{L}$ after an enzymatic hydrolysis using Celluclast $1.5 \mathrm{~L}$. Interestingly, the glucose concentration released was improved to $7.6 \mathrm{~g} / \mathrm{L}$ by using the mixture of "Celluclast + Viscozymes" enzymes after $48 \mathrm{~h}$ of hydrolysis. Nonetheless, in both assays, only the fibers rich in cellulose were hydrolyzed whereas agar was not solubilized [17].

Table 3. Glucose yield (g/100 g TS) obtained after $72 \mathrm{~h}$ of enzymatic hydrolysis of untreated and milled algae with an enzyme dosage of 3.4, 10 and $30 \mathrm{~g} / \mathrm{L}$.

\begin{tabular}{ccccc}
\hline Samples & Enzyme Loading & $\mathbf{3 . 4} \mathbf{~ g / L}$ & $\mathbf{1 0} \mathbf{~ g / L}$ & $\mathbf{3 0} \mathbf{~ g / L}$ \\
\hline \multirow{2}{*}{ Green alga: } & Untreated & $5.78 \pm 0.00$ & $12.45 \pm 0.47$ & $10.49 \pm 0.10$ \\
Ulva lactuca & Centrifugal milling & $5.79 \pm 0.52$ & $12.59 \pm 0.50$ & $10.71 \pm 0.13$ \\
& Vibro ball milling & $6.01 \pm 0.60$ & $12.63 \pm 0.46$ & $10.21 \pm 0.08$ \\
\hline Red alga: & Untreated & $1.48 \pm 0.04$ & $4.07 \pm 0.22$ & $4.12 \pm 0.13$ \\
Gelidium & Centrifugal milling & $3.87 \pm 0.17$ & $7.09 \pm 0.22$ & $6.68 \pm 0.70$ \\
sesquipedale & Vibro ball milling & $3.17 \pm 0.07$ & $5.45 \pm 0.10$ & $6.35 \pm 0.58$ \\
\hline
\end{tabular}




\subsection{Effect of Mechanical Pretreatments on Enzymatic Hydrolysis of Macroalgae}

The effect of mechanical pretreatments (i.e., centrifugal milling, vibro-ball milling) on total sugars released during enzymatic hydrolysis of untreated $U$. lactuca and G. sesquipedale was investigated (Figure 4). The results revealed that, whatever the enzymatic dosage, mechanical pretreatments did not have any effect on the total sugars released from green alga $U$. lactuca (Anova $p$-values $>0.05$ ) Conversely, total sugars released from G. sesquipedale increased after mechanical pretreatments (up to $126 \%$ and $129 \%$ after vibro-ball and centrifugal milling fractionation, respectively, Anova $p$-values $<0.05)$. Otherwise, fractionation was more effective in glucose releasing (up to $214 \%$ and $261 \%$ after vibro-ball and centrifugal milling, respectively). It is important to note also that mechanical fractionation seems to be less effective after increasing the enzymatic dosage from $3.4 \mathrm{~g} / \mathrm{L}$ to $30 \mathrm{~g} / \mathrm{L}$. Thus, glucose released from $\mathrm{G}$ sesquipedale increased after CM by $161 \%$ and $62 \%$ for 3.4 and $30 \mathrm{~g} / \mathrm{L}$ of enzymatic dosage, respectively. Furthermore, whatever the enzymatic dosage, $\mathrm{CM}$ was more effective than VBM in improving the total sugars and glucose released. Moreover, it is noteworthy that the high-energy requirement is one of the drawbacks of mechanical treatments. In a previous study, [18-20] reported that the energy requirement for CM (100 $\left.\mathrm{kWh} \mathrm{t}^{-1} \mathrm{TS}\right)$ was lower than that of VBM (2000 $\left.\mathrm{kWh} \mathrm{t}^{-1} \mathrm{TS}\right)$. Thus, CM was chosen for the performance of experimentation.

A
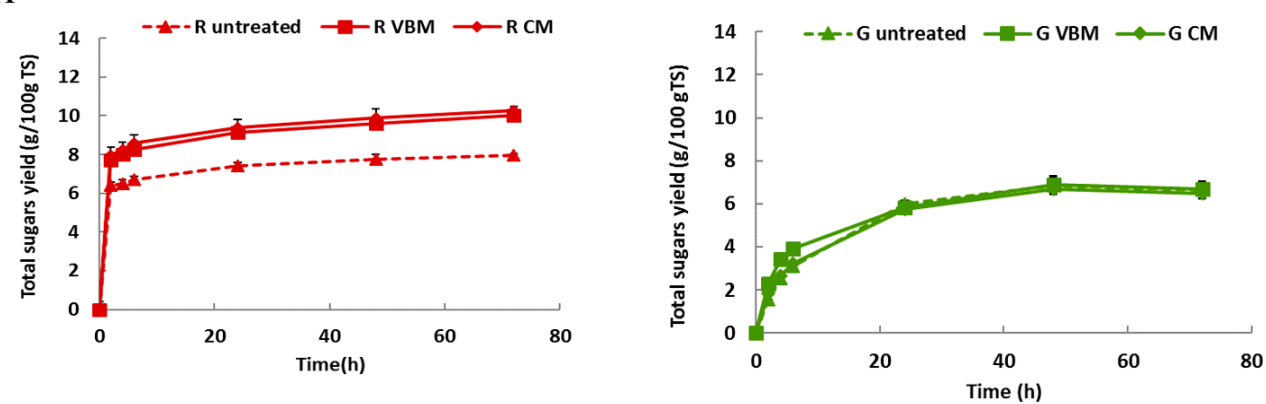

B
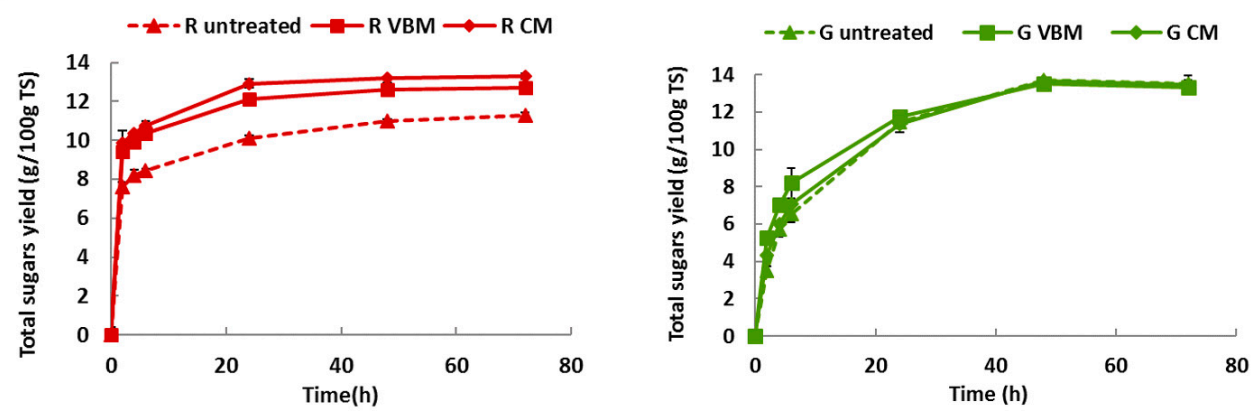

C
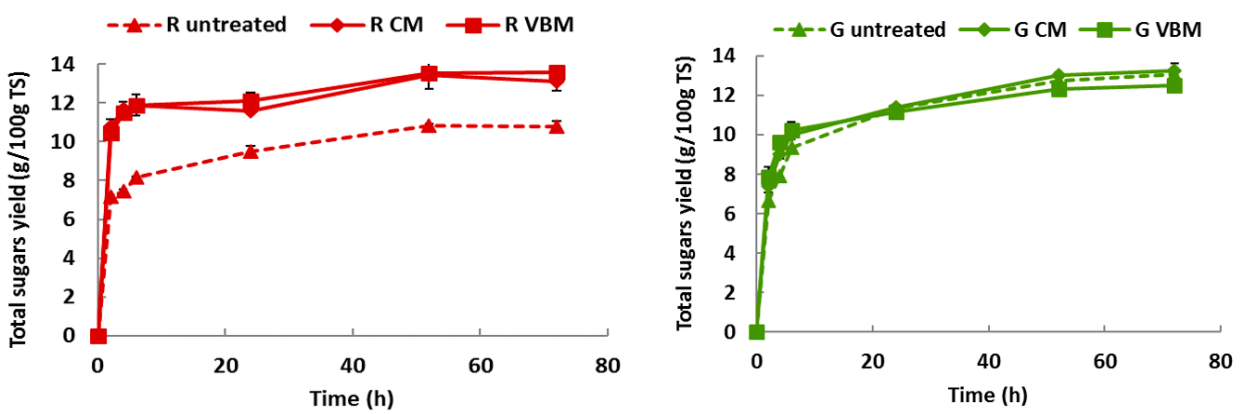

Figure 4. Total sugars released after $72 \mathrm{~h}$ of enzymatic hydrolysis for untreated and milled (G: Green, R: Red) macroalgae with an enzyme dosage of (A) 3.4; (B) 10 and (C) $30 \mathrm{~g} / \mathrm{L}$. Values correspond to mean \pm SD of measurement performed in duplicate. 


\subsection{Bioethanol Fermentation of U. lactuca and G. sesquipedale}

Taking into account the previous results, $\mathrm{CM}$ was chosen as mechanical treatment prior to a simultaneous saccharification and fermentation (SSF). Also, $10 \mathrm{~g} / \mathrm{L}$ was selected as the optimal enzymatic dosage of Haliatase and, thus, used in saccharification process. Bioethanol yields of untreated and centrifugal milled macroalgae were evaluated and compared through SSF experiments (Figure 5). CM treatment did not affect the ethanol production of U. lactuca with values around $6 \mathrm{~g}_{\text {eth }} / 100 \mathrm{~g}$ TS (Anova $p$-values of 0.35), confirming the enzymatic hydrolysis data (Figure 4). Conversely, the CM led to an enhancement of the ethanol yield of the red algae (from 1.95 to $3.51 \mathrm{~g} / 100 \mathrm{~g}$ TS, significantly different, with Anova $p$-values < 0.05). However, although bioethanol yield obtained with U. lactuca was higher than that of G. sesquipedale, the bioethanol conversion efficiency of the red one was higher, because the glucose content of red algae (9.62\%) is lower than that (15.2\%) of green algae (Table 1). Thus, after CM fractionation, $64 \%$ and $69 \%$ of bioethanol conversion efficiency (expressed in \% of the theoretical yield) (Table 4) was obtained for green and red algae, respectively. Furthermore, for algae strains, the galactose and xylose were not consumed. Such observation could be attributed to a diauxic effect commonly observed but it is not totally satisfactory, as the galactose consumption of the red algae did not start even after a total depletion of the glucose, so probably $72 \mathrm{~h}$ would be too short to initiate diauxic effect since Berlowska et al. (2017) [21] Berlowska et al., 2017 have demonstrated that actually, S. cerevisae ethanol red was capable to metabolize galactose but in absence of glucose. Nevertheless, despite the fact that a large number of yeast species can metabolize xylose, only $1 \%$ of strains convert xylose to ethanol [22]. Thus, it is important to find the most active yeast species for bioethanol fermentation of hexoses (other than glucose) and pentose sugars, in order to achieve higher ethanol yield.

(A)

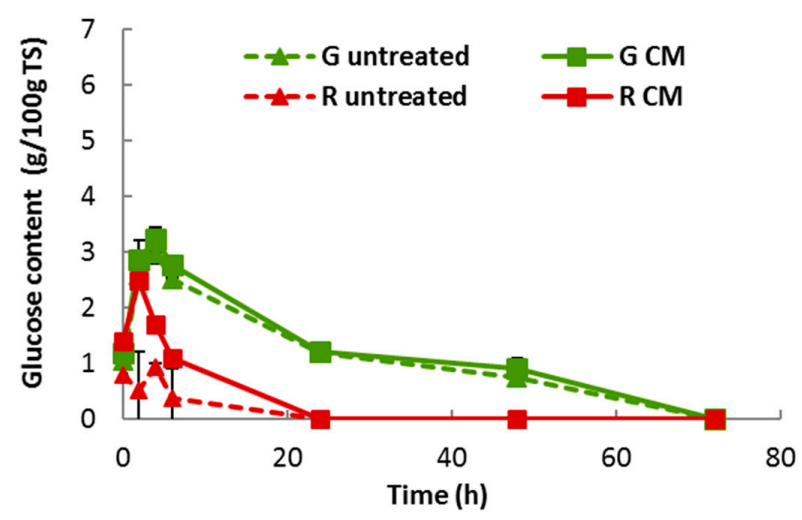

(B)

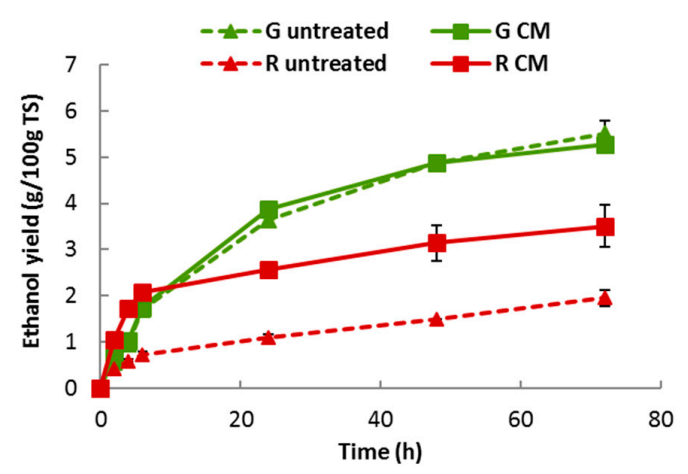

Figure 5. Simultaneous saccharification and fermentation of untreated and milled macroalgae (G: Green, R: Red) at an enzyme dosage of $10 \mathrm{~g} / \mathrm{L}$. (A) Glucose content (g/100 g TS); (B) Ethanol yield (g/100 g TS). Values correspond to mean \pm SD of measurement performed in duplicate. 
Table 4. Ethanol yield (g/100 g TS) obtained after $72 \mathrm{~h}$ of SSF of untreated and milled algae with an enzyme dosage of $10 \mathrm{~g} / \mathrm{L}$.

\begin{tabular}{ccccc}
\hline & \multicolumn{2}{c}{ Ethanol Yield (g/100 g TS) } & \multicolumn{2}{c}{ Ethanol Efficiency (\% Theoretical Yield *) } \\
\hline Samples & Untreated & Centrifugal Milling & Untreated & Centrifugal Milling \\
\hline Ulva lactuca & $5.51 \pm 0.29$ & $5.27 \pm 0.02$ & $67.2 \%$ & $64.3 \%$ \\
Gelidium & $1.95 \pm 0.17$ & $3.51 \pm 0.46$ & $38.2 \%$ & $68.7 \%$ \\
sesquipedale & & & & \\
\hline
\end{tabular}

* Theoretical ethanol yield: $8 \mathrm{~g} / 100 \mathrm{~g}$ TS and $5 \mathrm{~g} / 100 \mathrm{~g}$ TS for $U$. lactuca and G. sesquipedale respectively.

In this matter, Cho et al., 2014 [17], reported that glucose causes the repression of galactose uptake which decreased ethanol yield. The acclimation of galactose was then reported as the key of a fermentation process since it has allowed simultaneous utilization of glucose and galactose. In fact, ethanol yield doubled (from 0.21 to $0.44 \mathrm{~g} / 100 \mathrm{~g}$ TS) after using S. cerevisiae acclimated to high concentration of galactose.

Regarding treatment effects on ethanol fermentation, Schultz-Jensen et al. [10] investigated the ethanol fermentation of the green macroalga Chaetomorpha linum after wet oxidation, hydrothermal treatment, plasma, and ball milling for $48 \mathrm{~h}$ at $40{ }^{\circ} \mathrm{C}$. Interestingly, the best ethanol recovery was obtained after ball milling with an ethanol yield of $18 \mathrm{~g} / 100 \mathrm{~g} \mathrm{TS}$, corresponding to $78 \%$ of the theoretical ethanol yield.

\section{Materials and Methods}

\subsection{Macroalgae}

Red alga Gelidium sesquipedale and green alga Ulva lactuca were obtained from the Morocco coast. Once collected, samples were washed with tap water and further air-dried $(8 \% \mathrm{DM})$ and milled using a cutting mill to a particle size less than $2 \mathrm{~mm}$ (SM100 Retsch, Haan, Germany). Then, they were further milled using two equipments, characterized by different mechanical stresses, such as impact, compression, friction, and shear: (i) a centrifugal mill "CM" (Retsch ZM 200, Haan, Germany) with $0.25 \mathrm{~mm}$ screen size, operated at ambient temperature with a speed of $12000 \mathrm{rpm}$; (ii) a vibratory ball mill "VBM" (Retsch MM400, Haan, Germany) operated at ambient temperature, at a frequency of $15 \mathrm{~s}^{-1}$ for $5 \mathrm{~min}$.

\subsection{Enzymatic Cocktail}

The enzymatic cocktail (i.e., Haliatase enzyme) has been obtained from KURA BIOTECH SPA, (Puerto Varas, Chile) and it is derived from the hepatopanchreas of cultured abalone (Haliotis rufescens). It is a multi-enzymatic cocktail capable of degrading the cell walls of macroalgae by hydrolyzing most of their polysaccharides components. It is composed of mainly $\beta$-glucanase $(1875 \mathrm{U} / \mathrm{g})$, carragenase $(315 \mathrm{U} / \mathrm{g})$ and agarase $(440 \mathrm{U} / \mathrm{g})$.

\subsection{Enzymatic Hydrolysis}

Enzymatic hydrolysis of untreated and milled samples was performed in $40 \mathrm{~mL}$ of closed flasks (working volume of $20 \mathrm{~mL}$ ). An amount $(1 \mathrm{~g})$ of each sample (solid loading of $50 \mathrm{~g} / \mathrm{L}$ ), $2 \mathrm{~mL}$ of acetate buffer $(500 \mathrm{mM})$ and $15.8 \mathrm{~mL}$ of ultra-pure water were added to each flask. The $\mathrm{pH}$ was then adjusted to 5.5 with $\mathrm{NaOH}(1 \mathrm{~N})$ or $\mathrm{HCl}(2 \mathrm{~N})$. Finally, $1.2 \mathrm{~mL}$ of sodium azide (final concentration $1 \mathrm{~g} / \mathrm{L}$ ) and $1 \mathrm{~mL}$ of concentrated Haliatase enzyme were added to have final enzymatic concentrations of $3.4,10$ and $30 \mathrm{~g} / \mathrm{L}$, respectively. Flasks were kept at $37^{\circ} \mathrm{C}$ for $72 \mathrm{~h}$ with stirring $500 \mathrm{rpm}$. Samples were withdrawn at $0,2,4,6,24,48$ and $72 \mathrm{~h}$ and the corresponding supernatants were analyzed by HPLC (Waters corporation, Milford, CA, USA), equipped with a BioRad HPX-87H column (Biorad, Hercules, CA, USA) at $40{ }^{\circ} \mathrm{C}$, a refractive index detector at $40{ }^{\circ} \mathrm{C}$ and a $0.005 \mathrm{M} \mathrm{H}_{2} \mathrm{SO}_{4}$ solvent at 
$0.3 \mathrm{~mL} / \mathrm{min}$. Tests were performed in duplicate, to evaluate the amount of C5-C6 sugars released during the enzymatic hydrolysis.

Sugar yields ( $\left.\mathrm{g}_{i} / 100 \mathrm{~g} \mathrm{TS}\right)$ were calculated according to Equation (1):

$$
\text { Sugar " } i \text { " } \text { yield }_{t}=\left[C_{t} \text { sugar " } i \text { " } / C \text { solid }\right] \times 100
$$

where: $C_{\mathrm{t}}$ sugar " $i$ " (g $\mathrm{g}_{\text {sugar }}{ }^{\prime \prime}$ " $/ \mathrm{L}$ ) is the concentration of $\mathrm{C} 5$ and $\mathrm{C} 6$ sugars produced during hydrolysis, at time $\mathrm{t}$; $\mathrm{C}$ solid ( $\mathrm{g}$ TS/L) is the total solids concentration in the flask.

The analysis of variance (Anova) method was used to analyse the impact of the enzymatic dose and mechanical fractionation (CM and VBM) on both red and green algae, the confidence level considered was $95 \%$.

\subsection{Bioethanol Fermentation}

Bioethanol yields of untreated and milled (CM) macroalgae were evaluated and compared through simultaneous saccharification and fermentation (SSF) experiments. Tests were performed by using unsterilized samples, into $40 \mathrm{~mL}$ flasks (working volume of $20 \mathrm{~mL}$ ) closed with rubber septa and equipped with an air vent system, constituted of sterilized needle and filter, in order to evacuate the $\mathrm{CO}_{2}$ produced during the bioconversion. A lyophilized S. cerevisiae yeast strain (Ethanol $\operatorname{Red}^{\circledR}$, FERMENTIS, a division of S. I. LESAFFRE, Lille, France) was used as inoculum. For this purpose, lyophilized cells were previously washed and then suspended in sterilized distilled water to a concentration of $30 \mathrm{~g}$ TS/L. Each flask contained: $1 \mathrm{~g}$ TS of sample (solid loading of $50 \mathrm{~g} / \mathrm{L}$ ), $1 \mathrm{~mL}$ of concentrated Haliatase enzyme, to have an enzymatic concentration of $10 \mathrm{~g} / \mathrm{L}$ in each flask, $1 \mathrm{~mL}$ of yeast (30 g TS/L), $2 \mathrm{~mL}$ of nutrients, containing: $50 \mathrm{~g}$ TS/L yeast extract (Difco ${ }^{\circledR}$ ), $4 \mathrm{~g}$ TS/L urea, $0.5 \mathrm{~g}$ TS/L chloramphenicol and $50 \mathrm{mM}$ acetate buffer $(\mathrm{pH}=5)$. Flasks were incubated at $37^{\circ} \mathrm{C}$ for $72 \mathrm{~h}$ under stirring. Samples were withdrawn at $0,2,4,6,24,48$ and $72 \mathrm{~h}$ and the cell free supernatants were evaluated for ethanol and C6 sugars (i.e., glucose, galactose, fucose and rhamnose) concentrations by HPLC as previously mentioned.

Ethanol yields ( $\mathrm{g}_{\text {ethanol }} / 100 \mathrm{~g}$ TS) were calculated according to Equation (2):

$$
\text { Ethanol yield } t_{t}=\left[C_{t} \text { ethanol } / C \text { solid }\right] \times 100
$$

where $C_{\mathrm{t}}$ ethanol (gethanol $/ \mathrm{L}$ ) is the concentration of ethanol produced during SSF, at time $\mathrm{t}$; $C$ solid ( $\mathrm{g}$ TS/L) is the total solids concentration in the flask.

The analysis of variance (Anova) method was used to analyze the impact of mechanical fractionation (CM and VBM) on both red and green algae bioethanol fermentation, the confidence level considered was $95 \%$.

\subsection{Analytical Determinations}

Particle size distribution of untreated macroalgae was determined by a vibratory sieving apparatus (Analytical Sieve Shaker AS 200, Retsch ${ }^{\circledR}$, Haan, Germany) equipped with six sieves of different sizes $(1,0.8,0.71,0.56,0.32$ and $0.2 \mathrm{~mm})$. Particle size distribution of milled macroalgae was analyzed by a laser granulometry (MASTERSIZER 2000, Malvern Instrument, Orsay, France). Total Solids (TS), Volatile Solids (VS) and ash contents were determined according to APHA methods [22]. Ultimate analysis (C, N, H and S) was accomplished with an elemental analyzer (Elementar "VarioMacroCube", Elementar group, Langenselbold, Germany). Proteins content was estimated by multiplying N by 6.25 . Carbohydrates and uronic acids were determined according to a reduced scale hydrolysis procedure, based on the NREL Laboratory Analytical Procedure [23]. Briefly, $80 \pm 1 \mathrm{mg}$ of milled algae biomass was subjected to a two-stage sulfuric acid hydrolysis $\left(1 \mathrm{~h}\right.$ at $30{ }^{\circ} \mathrm{C}$ in $72 \mathrm{wt} \% \mathrm{H}_{2} \mathrm{SO}_{4}$, followed by $1 \mathrm{~h}$ at $121{ }^{\circ} \mathrm{C}$ in $4 \mathrm{wt} \% \mathrm{H}_{2} \mathrm{SO}_{4}$ for red algae and $3 \mathrm{~h}$ at $120{ }^{\circ} \mathrm{C}$ in $6 \mathrm{wt} \% \mathrm{H}_{2} \mathrm{SO}_{4}$ for the green algae). Samples were withdrawn at $1 \mathrm{~h}, 2 \mathrm{~h}$ and $3 \mathrm{~h}$ and the cell free supernatants were evaluated for sugars (i.e., glucose, xylose, arabinose, galactose, fucose, rhamnose) and uronic acids (galacturonic acid and 
glucuronic acid) concentrations by high-performance liquid chromatography by HPLC system (Waters corporation), equipped with a BioRad $\mathrm{HPX}-87 \mathrm{H}$ column at $40^{\circ} \mathrm{C}$, a refractive index detector at $40^{\circ} \mathrm{C}$ and a $0.005 \mathrm{M} \mathrm{H}_{2} \mathrm{SO}_{4}$ solvent at $0.3 \mathrm{~mL} / \mathrm{min}$. It is noteworthy that analytical determinations were performed in duplicate.

\section{Conclusions}

A comprehensive study was performed on the efficiency of a new natural enzymatic cocktail to hydrolyze polysaccharides of two types of seaweeds and produce bioethanol. The effects of two mechanical pretreatments were also tested for increasing bioethanol fermentation. The most effective enzymatic dosage for the saccharification process of green U. lactuca and red G. sesquipedale was $10 \mathrm{~g} / \mathrm{L}$ and the highest values of glucose released were obtained with green algae after $72 \mathrm{~h}$ of enzymatic hydrolysis. Centrifugal milling was more effective in hydrolyzing red G. sesquipedale compared to vibro-ball milling, while the mechanical pretreatments applied did not show any effect on green U. lactuca. However, green U. lactuca showed the highest bioethanol yield compared to red G. sesquipedale.

Acknowledgments: The authors are grateful to the LipPolGreen Platform of UMR IATE and (INRA Montpellier) for her help in biochemical analysis and fermentation and INRA for the financial support. The authors are grateful to KURA BIOTECH SPA (Chile) for giving us the Haliatase enzyme cocktail.

Author Contributions: A.B. and F.M. conceived and designed the experiments; S.A. and C.S. performed the experiments; E.D., A.B. and F.M. analyzed the data; S.A. contributed analysis tools; all authors wrote the paper.

Conflicts of Interest: The authors declare no conflict of interest

\section{Abbreviations}

$\begin{array}{ll}\text { VBM } & \text { Vibro-Ball Milling } \\ \text { CM } & \text { Centrifugal Milling } \\ \text { TS } & \text { Total Solids } \\ \text { VS } & \text { Volatile Solids } \\ \text { SSF } & \text { Simultaneous Saccharification Fermentation }\end{array}$

\section{References}

1. John, R.P.; Anisha, G.S.; Nampoothiri, K.M.; Pandey, A. Micro and macroalgal biomass: A renewable source for bioethanol. Bioresour. Technol. 2011, 102, 186-193. [CrossRef] [PubMed]

2. Borines, M.G.; de Leon, R.L.; Cuello, J.L. Bioethanol production from the macroalgae Sargassum spp. Bioresour. Technol. 2013, 138, 22-29. [CrossRef] [PubMed]

3. Pham, T.N.; Um, Y.; Yoon, H.H. Pretreatment of macroalgae for volatile fatty acid production. Bioresour. Technol. 2013, 146, 754-757. [CrossRef] [PubMed]

4. Lee, J.Y.; Li, P.; Lee, J.; Ryu, H.J.; Oh, K.K. Ethanol production from Saccharina japonica using an optimized extremely low acid pretreatment followed by simultaneous saccharification and fermentation. Bioresour. Technol. 2013, 127, 119-125. [CrossRef] [PubMed]

5. Park, J.-H.; Hong, J.-Y.; Jang, H.C.; Oh, S.G.; Kim, S.-H.; Yoon, J.-J.; Kim, Y.J. Use of Gelidium amansii as a promising resource for bioethanol: A practical approach for continuous dilute-acid hydrolysis and fermentation. Bioresour. Technol. 2012, 108, 83-88. [CrossRef] [PubMed]

6. Sambusiti, C.; Bellucci, M.; Zabaniotou, A.; Beneduce, L.; Monlau, F. Algae as promising feedstocks for fermentative biohydrogen production according to a biorefinery approach: A comprehensive review. Renew. Sustain. Energy Rev. 2015, 44, 20-36. [CrossRef]

7. Jung, K.A.; Lim, S.-R.; Kim, Y.; Park, J.M. Potentials of macroalgae as feedstocks for biorefinery. Bioresour. Technol. 2013, 135, 182-190. [CrossRef] [PubMed]

8. Meinita, M.D.N.; Hong, Y.-K.; Jeong, G.-T. Comparison of sulfuric and hydrochloric acids as catalysts in hydrolysis of Kappaphycus alvarezii (cottonii). Bioprocess Biosyst. Eng. 2012, 35, 123-128. [CrossRef] [PubMed] 
9. Wang, X.; Liu, X.; Wang, G. Two-stage Hydrolysis of Invasive Algal Feedstock for Ethanol FermentationF. J. Integr. Plant Biol. 2011, 53, 246-252. [CrossRef] [PubMed]

10. Schultz-Jensen, N.; Thygesen, A.; Leipold, F.; Thomsen, S.T.; Roslander, C.; Lilholt, H.; Bjerre, A.B. Pretreatment of the macroalgae Chaetomorpha linum for the production of bioethanol-Comparison of five pretreatment technologies. Bioresour. Technol. 2013, 140, 36-42. [CrossRef] [PubMed]

11. Monlau, F.; Sambusiti, C.; Antoniou, N.; Zabaniotou, A.; Solhy, A.; Barakat, A. Pyrochars from bioenergy residue as novel bio-adsorbents for lignocellulosic hydrolysate detoxification. Bioresour. Technol. 2015, 187, 379-386. [CrossRef] [PubMed]

12. Delgenes, J.P.; Moletta, R.; Navarro, J.M. Effects of lignocellulose degradation products on ethanol fermentations of glucose and xylose by Saccharomyces cerevisiae, Zymomonas mobilis, Pichia stipitis, and Candida shehatae. Enzym. Microb. Technol. 1996, 19, 220-225. [CrossRef]

13. Motte, J.C.; Delenne, J.Y.; Rouau, X.; Mayer-Laigle, C. Mineral-vegetal co-milling: An effective process to improve lignocellulosic biomass fine milling and to increase interweaving between mixed particles. Bioresour. Technol. 2015, 192, 703-710. [CrossRef] [PubMed]

14. Kim, N.-J.; Li, H.; Jung, K.; Chang, H.N.; Lee, P.C. Ethanol production from marine algal hydrolysates using Escherichia coli KO11. Bioresour. Technol. 2011, 102, 7466-7469. [CrossRef] [PubMed]

15. Trivedi, N.; Gupta, V.; Reddy, C.R.K.; Jha, B. Enzymatic hydrolysis and production of bioethanol from common macrophytic green alga Ulva fasciata Delile. Bioresour. Technol. 2013, 150, 106-112. [CrossRef] [PubMed]

16. Jard, G.; Marfaing, H.; Carrère, H.; Delgenes, J.P.; Steyer, J.P.; Dumas, C. French Brittany macroalgae screening: Composition and methane potential for potential alternative sources of energy and products. Bioresour. Technol. 2013, 144, 492-498. [CrossRef] [PubMed]

17. Cho, H.; Ra, C.-H.; Kim, S.-K. Ethanol Production from the Seaweed Gelidium Amansii, Using Specific Sugar Acclimated Yeasts. J. Microbiol. Biotechnol. 2014, 24, 264-269. [CrossRef] [PubMed]

18. Motte, J.-C.; Sambusiti, C.; Dumas, C.; Barakat, A. Combination of dry dark fermentation and mechanical pretreatment for lignocellulosic deconstruction: An innovative strategy for biofuels and volatile fatty acids recovery. Appl. Energy 2015, 147, 67-73. [CrossRef]

19. Barakat, A.; De Vries, H.; Rouau, X. Dry fractionation process as an important step in current and future lignocellulose biorefineries: A review. Bioresour. Technol. 2013, 134, 362-373. [CrossRef] [PubMed]

20. Barakat, A.; Chuetor, S.; Monlau, F.; Solhy, A.; Rouau, X. Eco-friendly dry chemo-mechanical pretreatments of lignocellulosic biomass: Impact on energy and yield of the enzymatic hydrolysis. Appl. Energy 2014, 113, 97-105. [CrossRef]

21. Berlowska, J.; Pielech-Przybylska, K.; Balcerek, M.; Cieciura, W.; Borowski, S.; Kregiel, D. Integrated Bioethanol Fermentation/Anaerobic Digestion for Valorization of Sugar Beet Pulp. Energies 2017, 10, 1255. [CrossRef]

22. American Public Health Association (APHA). Standard Methods for the Examination of Water and Wastewater, 21st ed.; American Public Health Association: Washington, DC, USA, 2005.

23. Wychen, V.; Laurens, L.M.L. Determination of Total Carbohydrates in Algal Biomass; Laboratory Analytical Pro-Cedure (LAP): Golden, CO, USA, 2013.

Sample Availability: Samples of the compounds are not available from the authors. 